\title{
PERUBAHAN STATUS JENIS KELAMIN DALAM PERSPEKTIF HUKUM POSITIF DI INDONESIA
}

\author{
I Nyoman Satria Perwira, Ida Ayu Putu Widiati, Diah Gayatri Sudibya \\ Fakultas Hukum Universitas Warmadewa, Denpasar-Bali, Indonesia \\ satriaperwira020299@gmail.com, widiati_dayu@yahoo.co.id, diahgayatrisudibya@gmail.com
}

\begin{abstract}
Abstrak
Kelainan seksual disebabkan adanya kelainan pada hormon seseorang, transeksual memiliki keinginan untuk melakukan perubahan jenis kelaminnya dengan cara operasi. hal tersebut dapat dilakukan sesuai dengan prosedur yang berlaku. Sampai saat ini, Indonesia belum memiliki pengaturan hukum mengenai perubahan status jenis kelamin seorang transgender yang melakukan operasi jenis kelamin, dikarenakan belum ada aturan tentang perubahan status jenis kelamin maka menimbulkan kekosongan norma dan menyebabkan masyarakat masih memandang sebelah mata seorang transgender. Perubahan status jenis kelamin dapat dilakukan dengan mengajukan permohonan tersebut di pengadilan Negeri. Penelitian ini bertujuan menjelaskan prosedur perubahan jenis kelamin di Indonesia dan legalitas perubahan jenis kelamin dari sisi hukum positif di Indonesia. Penelitian ini menggunakan penelitian normatif dan pendekatan konseptual. Adapun sumber bahan hukum yang digunakan yaitu bahan hukum primer, sekunder dan tersier. Data diperoleh melalui teknik dokumentasi dan pencatatan, selanjutnya dianalisis secara sistematis. Hasil penelitian menunjukkan bahwa Perubahan status jenis kelamin di Indonesia memiliki beberapa tahapan seperti menjalani konseling, pemeriksaan psikiatri, pemeriksaan andrology, pemeriksaan fisik, konseling psikoreligius dan lainnya yang bersifat administrasi. Tidak semua orang dapat melakukan operasi kelamin ada beberapa syarat yang harus dipenuhi untuk mendapatkan legalitas atau kepastian hukum seorang transgender dapat mengajukannya di pengadilan negeri setempat hal ini dilakukan untuk mendapatkan pengakuan secara hukum
\end{abstract}

Kata kunci: Hukum Positif, Perubahan Status Jenis Kelamin, Transeksual

\begin{abstract}
Sexual abnormalities are caused by abnormalities in a person's hormones. Transsexuals have the desire to change their sex by means of surgery, which can be done in accordance with applicable procedures. Until now, Indonesia does not have a legal regulation regarding changing the sex status of a transgender person who performs sex surgery, because there are no rules on changing gender status, it creates a vacuum of norms and causes people to still underestimate a transgender person. Change of gender status can be made by submitting the application to the District Court. This study aims to explain the procedure for sex change in Indonesia and the legality of sex change from a positive legal perspective in Indonesia. This research used normative research and a conceptual approach. The sources of legal materials used were primary, secondary, and tertiary legal materials. Data obtained through documentation and recording techniques then analyzed systematically. The results showed that the change in gender status in Indonesia has several stages such as undergoing counseling, psychiatric examinations, andrology examinations, physical examinations, psychoreligious counseling, and others of an administrative nature. Not everyone can perform genital surgery, there are several conditions that must be met to get legality or legal certainty that a transgender person can file it in a local district court, this is done to get legal recognition.
\end{abstract}

Keywords: Positive Law, Change in Gender Status, Transsexual

\section{PENDAHULUAN}

Seorang perempuan dan laki-laki pada dasarnya berbeda dari sifat maupun fisik namun hukum di Indonesia tidak pernah memperlakukan seseorang dengan perlakuan yang berbeda $\mathrm{Hal}$ ini dapat terjadi mengingat Indonesia merupakan negara hukum dengan berpedoman kepada Pancasila (Z. Harahap, 2014). Setiap manusia sudah dibekali haknya sejak ia lahir tanpa ada seorangpun yang dapat merampas hak tersebut dan setiap manusia berhak untuk mendapatkan kehidupan yang layak tanpa adanya diskriminasi. Namun beberapa orang masih sering mengganggu hak orang lain Seperti halnya ada seorang atau golongan tertentu yang menghakimi seseorang yang mempunyai kelainan secara seksual. Kelainan seksual biasa disebut sebagai lesbian gay biseksual dan transgender (LGBT) di lingkungan Indonesia sendiri hal ini sudah sering ditemui namun hal tersebut masih belum bisa 
diterima oleh masyarakat sekitar Namun jika ditinjau dari ilmu Kesehatan LGBT tidak termasuk gangguan kejiwaan tetapi hal ini dapat dikatakan karena adanya kelainan hormonal di dalam tubuh seseorang LGBT tersebut (Yudiyanto, 2016).

Untuk mendapatkan pengakuan yang lebih dimasyarakat dan di mata hukum kaum beberapa kaum LGBT sudah melakukan operasi kelamin hal ini dilakukan agar kepribadiannya semakin terlihat jelas (R. D. K. A. Harahap, 2016). Kaum LGBT juga mengharapkan hidup seperti layaknya seseorang yang normal. Untuk mewujudkan hal tersebut mereka harus mengganti jenis kelamin mereka, seperti layaknya seseorang harus melanjutkan hidupnya ke pernikahan atau perkawinan yang mana perkawinan hanya akan bisa dilaksanakan jika terdiri dari seorang perempuan dan laki-laki Untuk mewujudkan pernikahan kaum LGBT selain mengganti jenis alat kelaminnya mereka juga harus mengganti status jenis kelaminnya secara hukum di Indonesia. Namun di Indonesia sendiri belum adanya pengaturan yang mengatur mengenai perubahan status jenis kelamin Saat seseorang ingin mengajukan hal tersebut hakim tidak boleh menolaknya sebab hakim dianggap tahu akan segalanya Berdasarkan hal tersebut tentunya hal ini akan mengacu pada Undang-Undang yang telah berlaku dan yurisprudensi

Berkaitan dengan penelitian ini, ada beberapa penelitian terdahulu yang melakukan penelitian yang relevan dengan penelitian ini yaitu (Abdullah, 2013); (Kurniawati et al., 2017); (Singadimedja et al., 2019) mengungkapkan bahwa Opersi jenis kelamin dibenarkan jika bertujuan untuk memeprbaiki alat kelamin, selanjutnya perkawinan transeksual biasa disahkan dicatatan sipil apa bila telah mendapat penetapan pengadilan dan telah memenuhi syarat-syarat perkawinan tersebut. Terkait dengan hal itu, peneliti ingin melakukan penelitian dengan tujuan untuk menjelaskan prosedur proses perubahan jenis kelamin di Indonesia dan menjelaskan legalitas perubahan jenis kelamin dari sisi hukum positif di Indonesia

\section{METODE PENELITIAN}

Penelitian ini menggunakan penelitian hukum normatif yang mana mengacu pada studi kepustakaan di bidang hukum dengan menggunakan pendekatan masalah secara konseptual dan pendekatan kasus yang terjadi. Ada beberapa bahan hukum yang digunakan yaitu bahan hukum primer berpedoman terhadap undang-undang dan keputusan yang mengikat, bahan hukum sekunder yaitu bahan hukum yang didapatkan melalui jurnal hukum buku hukum serta internet yang memuat mengenai perubahan status jenis kelamin dalam perspektif hukum positif di Indonesia dan bahan tersier didapatkan melalui kamus hukum serta ensiklopedia yang berkaitan mengenai informasi hukum. Teknik pengumpulan bahan hukum dilakukan dengan cara mencatat mengutip membaca maupun meringkas literatur yang mengacu terhadap perubahan status jenis kelamin di indonesia. Selanjutnya bahan hukum dianalisis secara sistematis dan mengaitkannya dengan bahan hukum lainnya.

\section{HASIL DAN PEMBAHASAN}

\section{Prosedur Proses Perubahan Jenis Kelamin di Indonesia}

Setiap manusia telah diciptakan berbeda, perbedaan itu dapat dilihat dari fisik seorang perempuan dan laki-laki. Namun sangat disayangkan hal ini tidak selalu menentukan perbedaan antara perempuan dan laki-laki. Dapat dijelaskan secara rinci yakni seorang perempuan berpenampilan seperti laki-laki dan sebaliknya, tentu hal ini dapat dikatakan ketidaknormalan hormon seseorang, di Indonesia sendiri masih tabu akan hal tersebut seringnya seseorang mendapatkan perlakukan yang buruk jika menyimpang dari jenis kelaminnnya yang sesungguhnya. Indonesia sendiri sudah sering dijumpai perempuan berpakaian seperti laki-laki dan sebaliknya, kebingungan jenis kelamin yang mereka alami dapat disebut sebagai gejala transeksual atau transgender yang mana mereka tidak memiliki kepuasan dengan alat kelamin yang mereka miliki. Ketertarikan dengan lawan jenis pun bisa saja menghilang dan tergantikan dengan menyukai sesama jenis (Maesaroh, 2017).

Dari hal tersebut inilah mereka memiliki perbedaan antara sifat biologis dan jenis kelaminnya Berdasarkan ilmu kesehatan perubahan jenis kelamin ini bisa terjadi yang diakibatkan oleh kromosom di tubuh seseorang perempuan lebih berkembang dari kromosom laki-laki dan sebaliknya hal ini ditandai dengan organ kelaminnya tidak berkembang secara maksimal. Meskipun di Indonesia sendiri masih tabu dengan hal ini namun ada beberapa kasus transgender yang melakukan operasi jenis kelamin dan membutuhkan pengakuan hukum tetap agar mereka dapat hidup selayaknya orang normal tanpa dipandang sebelah mata Tetapi mengingat indonesia yang menjunjung 
tinggi norma-norma yang berlaku maka para pelaku transgender dianggap sebagai bentuk pelanggaran norma (Zaeni, 2019).

Transgender pada umumnya tidak dapat disebut sebagai gangguan mental namun jika transgender mendapatkan perlakuan yang buruk maka seseorang tersebut dapat memiliki gangguan kejiwaan. Gangguan identitas jenis kelamin (gender identity) yakni keadaan psikologis seseorang yang mencerminkan perasaanya (inner sense) dari diri seorang laki-laki atau perempuan yang mana identitas jenis kelamin hanya dapat ditentukan dari sikap pola perilaku serta fisik seseorang. Beberapa pelaku transeksual telah melakukan operasi guna merubah jenis alat kelamin mereka hal ini dilakukan agar dapat hidup dengan layak dan melanjutkan kehidupannya yaitu perkawinan Namun perlakukan masyarakat yang masih belum menghargai dan menerima kehadiran kaum LGBT akan menimbulkan konflik batin terhadap pelaku LGBT dan hal ini telah melanggar kenyamanan kehidupan seseorang dan bertentangan dengan hak asasi manusia Sesungguhnya setiap orang berhak untuk memilih jalan hidupnya karena manusia dilahirkan dengan bebas serta harkat dan martabat manusia memiliki kedudukan yang sama dimata hukum (Qomar, 2018).

Pergantian jenis kelamin dapat dilakukan oleh setiap orang yang merasa dirinya memiliki kelainan seksua, hal ini dapat dilakukan atas permintaan dari pihak yang bersangkutan dan disetujui oleh psikiater psikolog, ahli hukum, ahli agama, dokter ahli andrologi, dokter ahli bedah, dokter ahli kebidanan dan kandungan dokter ahli anestesi. Tidak semua permintaan operasi jenis kelamin dapat dikabulkan oleh tim ahli medis jika pemeriksaan andrologi dan psikologi pasien normal maka yang bersangkutan disarankan untuk menjalani terapi re- orientasi seksual.

Tahapan untuk mereka yang ingin melakukan operasi jenis kelamin harus menjalani konseling melakukan pemeriksaan psikiatri menjalani pemeriksaan antrologi pemeriksaan fisik Hal ini dilakukan bukan hanya untuk semata-mata mengubah jenis kelaminnya namun memastikan apakah ia berhak untuk mengubah jenis kelaminnya. Operasi penggantian alat kelamin biasa disebut sebagai genitoplasty. Jika operasi jenis alat kelamin telah dilakukan tahap berikutnya dengan cara mengajukan permohonan terhadap pengadilan untuk mengganti status jenis kelaminnya agar sah secara hukum dan tidak lagi mendapatkan perlakuan yang buruk di masyarakat. Hal ini dapat dilakukan dengan perubahan secara administrasi kependudukan dengan merubah akta pencatatan sipil yang mengenai kelahiran kematian perkawinan perceraian dan pengakuan anak. Melalui cara operasi jenis kelamin dan mengganti status jenis kelamin secara hukum maka pelaku transgender akan memiliki kekuatan hukum tetap dan diakui legalitasnya.

\section{Legalitas Perubahan Jenis Kelamin dari Sisi Hukum Positif di Indonesia}

Keputusan seseorang untuk melakukan perubahan jenis kelamin merupakan hal yang cukup sulit, terlebih dahulu harus melakukan beberapa konseling dan mengikuti prosedur yang berlaku. Meskipun beberapa transgender merasa tidak perlu sampai merubah jenis kelamin namun hal ini dilakukan untuk menyembuhkan diri dan jika para transeksual ingin melakukan perkawinan agar dapat disahkan secara hukum Jika ditinjau dari sisi hukum positif di Indonesia, hal ini belum ada pengaturannya tentunya dapat menimbulkan kekosongan norma yang mana seorang transgender tidak memiliki kepastian hukum serta kejelasan mengenai perubahan jenis kelaminnya.

Seseorang yang ingin melakukan perubahan status jenis kelaminnya dapat ditinjau dari Undang-Undang Republik Indonesia Nomor 39 Tahun 1999 tentang Hak Asasi Manusia dan UndangUndang Republik Indonesia Nomor 24 Tahun 2013 tentang Perubahan Atas Undang-Undang No 23 Tahun 2006 tentang Administrasi Kependudukan dan Yurisprudensi Mengacu terhadap HAM dikarenakan setiap orang bebas untuk mengekspresikan jiwanya semasih hal tersebut tidak mengganggu ketentraman orang lain (Abbad, 2005).

Selain HAM sebagai acuan untuk melindungi pelaku transeksual yang ingin mengubah status jenis kelaminnya hal ini juga dapat dikaitkan dengan undang- undang administrasi kependudukan yang mana hal ini mengatur mengenai penataan serta penerbitan dokumen dan data kependudukan melalui pendaftaran penduduk pencatatan sipil dalam pasal 1 Angka 17 tentang administrasi kependudukan memang tidak menyebutkan mengenai perubahan jenis kelamin sebagai peristiwa penting namun dalam pasal 56 ayat 1 menyebutkan bahwa peristiwa penting dapat dilakukan apabila sudah mendapatkan putusan tetap oleh pengadilan negeri. Seorang transeksual pastinya akan melanjutkan kehidupannya dengan cara melakukan perkawinan tahap untuk melakukan perubahan jenis kelamin dan status jenis kelamin maka seorang transeksual dapat melangsungkan pernikahannya 
Pernikahan dianggap sakral selain memenuhi kebutuhan biologis seseorang yang mana dari perkawinan ini diharapkan memiliki keturunan (Moch Isnaeni 2016).

Dalam hal ini indonesia memiliki pengaturan tersendiri mengenai perkawinan yang mana diatur dalam Pasal 1 Undang-Undang Republik Indonesia No 1 Tahun 1974 yang menyebutkan jika perkawinan dilakukan antara pria dan wanita Jika seorang transeksual yang belum merubah jenis kelaminnya secara hukum maupun medis maka ia belum bisa melangsungkan perkawinan jika ia akan menikah dengan sesama jenis karena di Indonesia hal tersebut masih dianggap tabu. Salah satu contoh mengenai pengajuan perubahan status jenis kelamin di Indonesia terdapat dalam Putusan Hakim Nomor 117/Pdt P/2020/PN Jkt Utr yang mana seseorang bernama Theodora Victory Divine Grace seorang perempuan yang ingin mendapatkan pengakuan hukum bahwa ia telah sah menjadi seorang laki-laki setelah melakukan operasi jenis kelamin Bukti bahwa ia telah melakukan operasi jenis kelamin dan mengikuti prosedurnya dibuktikan dengan pernyataan medis dari dokter spesialis yang menanganinya. Hal ini dilakukan karena Theodora merasa bahwa ia lebih ingin menjadi seorang lakilaki dapat dilihat dari penampilan sehari-harinya pengakuan ini didapat berdasarkan keterangan para saksi di persidangan Prosedur yang dilakukan pemohon dengan cara menyiapkan kartu tanda penduduk sebelumnya bukti akta kelahiran kartu keluarga surat keterangan dokter dengan pasien atas nama Theodora Victory Divine Grace surat pusat operasi plastik estetik. Permohonan dari Theodora Victory Divine Grace menjadi Theodore Victory Divine Grace dikabulkan oleh pengadilan negeri jakarta yang mana ia telah sah sebagai laki-laki memerintahkan panitera untuk mengirimkan salinan penetapan ini kepada Kantor Catatan Sipil Wilayah Jakarta Maka setelah ia melakukan operasi kelamin dan melakukan pengajuan terhadap pengadilan negeri jakarta agar memiliki kekuatan hukum yang tetap. Pada kasus ini komnas HAM meminta agar pemohon perubahan status jenis kelamin tidak didiskriminasi.

\section{SIMPULAN DAN SARAN}

\section{Simpulan}

Dari hasil analisis data di atas, dapat disimpulkan bahwa persyaratan dan prosedur perubahan jenis kelamin di Indonesia dapat dilakukan apabila sesuai dengan prosedur yang berlaku. Hal ini dilakukan oleh seorang transeksual guna untuk memperjelas jenis kelaminnya karena di Indonesia sering memandang sebelah mata seorang transeksual dan masih dianggap sebagai hal yang tabu, sehingga timbul niat seorang transeksual untuk merubah jenis kelaminnya. Persyaratan medis untuk merubah jenis kelaminnya yaitu harus melakukan beberapa tahap seperti pemeriksaan kejiwaan atau psikolog jika seorang transgender dianggap tidak perlu melakukan operasi karena hasil dari pemeriksaan psikolognya normal maka akan diarahkan supaya tidak melakukan hal tersebut. Prosedur hukum yang dilakukan dengan cara melakukan pengajuan permohonan terhadap pengadilan negeri setempat dengan melampirkan kartu tanda penduduk, kartu keluarga, akta kelahiran dan surat medis dari dokter ahli bedah, yanmg kedua Legalitas perubahan jenis kelamin dari sisi hukum positif di Indonesia belum diatur secara jelas hal ini menimbulkan kekosongan norma namun hakim tidak boleh menolak menangani permohonan ini dengan alasan tidak ada dasar hukumnya.

\section{Saran}

Dari hasil penelitian ini, terdapat dua saran yaitu peran pemerintah diharapkan merancang dan membuat peraturan perundang-undangan yang mengatur tentang perubahan jenis kelamin serta memperjelas dan mempertegas dari sisi hukum positif lainnya mengenai perubahan jenis kelamin ini dikarenakan juga peraturan ini belum diatur dalam Perundang-Undangan sehingga menimbulkan sesuatu kekosongan norma yang mengakibatkan seorang transgender yang sudah merubah jenis kelamin tidak memiliki kejelasan secara identitas maupun legalitas kepastian hukum, yang kedua Peran masyarakat diharapkan mengetahui bahwa kondisi dari seorang transgender tidak ingin juga memiliki ketidakpastian dalam jenis kelaminnya, hal ini tidak dikehendaki pula oleh dalam diri seorang transgender dikarenakan kondisi tersebut dibawanya sejak ia lahir. Sebaiknya seorang transgender didampingi dalam permasalahan yang sedang dihadapinya tersebut

\section{DAFTAR PUSTAKA}

Abbad, J. A. dan H. (2005). Hak Asasi Manusia dalam Konstitusi Indonesia. Jakarta: Sinar Grafika.

Abdullah, A. D. (2013). Legal Reasoning Hukum Operasi Ganti Kelamin Penderita Transeksual (Studi 
Komparasi Antara Hukum Islam dan Hukum Perdata). Istinbath, 12(1), 221-240.

Harahap, R. D. K. A. (2016). LGBT di Indonesia: Perspektif Hukum Islam, Ham, Psikologi dan Pendekatan Mașlaḥah. Al-Ahkam, 26(2), 223-248.

Harahap, Z. (2014). Hukum Acara Peradilan Tata Usaha Negara. Depok: PT Rajagrafindo Persada.

Kurniawati, M., Widanarti, H., \& Aminah. (2017). Tinjauan Yuridis Status Keperdataan Pelaku Transeksual (Studi Kasus Penetapan Pengadilan Negeri Kabupaten Semarang Nomor 518/Pdt.P/2013/Pn.Ung). Jurnal Law, 6(2), 1-19.

Maesaroh, S. (2017). Operasi Kelamin Transeksual dalam Kajian Hukum Islam. Yogyakarta:Thafa Media. Qomar, N. (2018). Hak Asasi Manusia dalam Negara Hukum Demokrasi. Jakarta: Sinar Grafika.

Singadimedja, H. N., Karsona, A. M., \& Azzahra, A. F. (2019). Identitas Baru Transeksual dan Status Hukum Perkawinannya. Jurnal Ilmiah Hukum De’Jure, 4(1), 14-30.

Yudiyanto. (2016). Fenomena Lesbian, Gay, Biseksual dan Transgender (LGBT) di Indonesia Serta Upaya Pencegahannya. Journal of Chemical Information and Modeling, 5(1).

Zaeni, A. (2019). Pengantar Hukum Indonesia. Jakarat: Raja Grafindo. 